\title{
ERRATA
}

\section{Corrections of the text and the figure in the paper "Effect of Strain Rate on the Hydrogen Embrittlement Property of Ultra High-strength Low Alloy TRIP-aided Steel" \\ [ISIJ International, Vol. 58 (2018), No. 4, pp. 751-759]}

\author{
Tomohiko HOJO, ${ }^{1)}$ Riko KIKUCHI, ${ }^{2)}$ Hiroyuki WAKI, ${ }^{3)}$ Fumihito NISHIMURA, ${ }^{3)}$ Yuko UKAI ${ }^{4)}$ and Eiji AKIYAMA ${ }^{1)}$ \\ 1) Institute for Materials Research, Tohoku University, 2-1-1 Katahira, Aoba-ku, Sendai, 980-8577 Japan. \\ 2) Graduate Student, Iwate University, 4-3-5 Ueda, Morioka, 020-8551 Japan. \\ 3) Faculty of Science and Engineering, Iwate University, 4-3-5 Ueda, Morioka, 020-8551 Japan. \\ 4) Sumika Chemical Analysis Service, Ltd., 9-1 Kitasode, Sodegaura, Chiba, 299-0266 Japan.
}

DOI: http://dx.doi.org/10.2355/isijinternational.ISIJINT-2017-576

The authors have found that the explanation in introduction, result of mechanical property and the Figures 2 and 9 reported in the above paper are incorrect. The authors would like to correct the text and figures as follows:

The text in page 751 lines 7 on right-hand column is currently shown as:

ductility increased with decreasing the strain rate.

That should read as:

ductility decreased with decreasing the strain rate.

Also, Figs. 2 and $\mathbf{9}$ should be replaced by the following figures: 

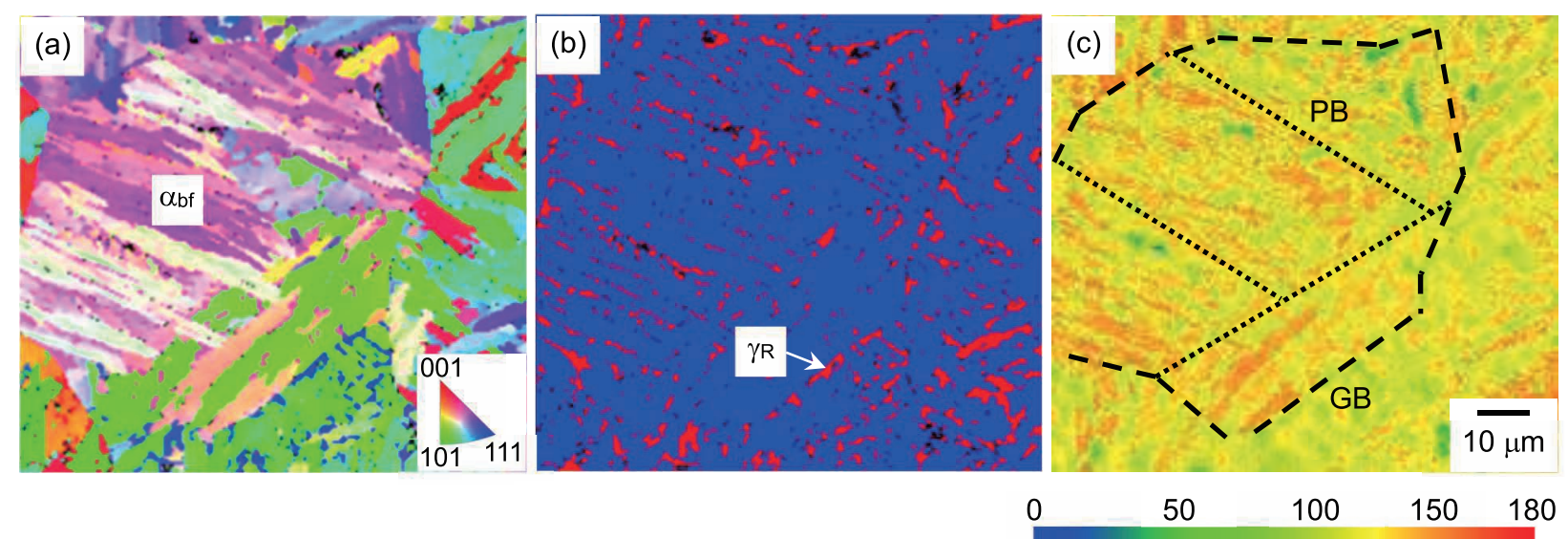

Fig. 2. (a) Inverse pole figure (IPF) map, (b) phase map and (c) image quality (IQ) distribution map of TBF steel. $\alpha_{\mathrm{bf}}$ and $\gamma_{\mathrm{R}}$ represent bainitic ferrite and retained austenite, and GB and PB denote prior austenite grain and packet boundaries, respectively.
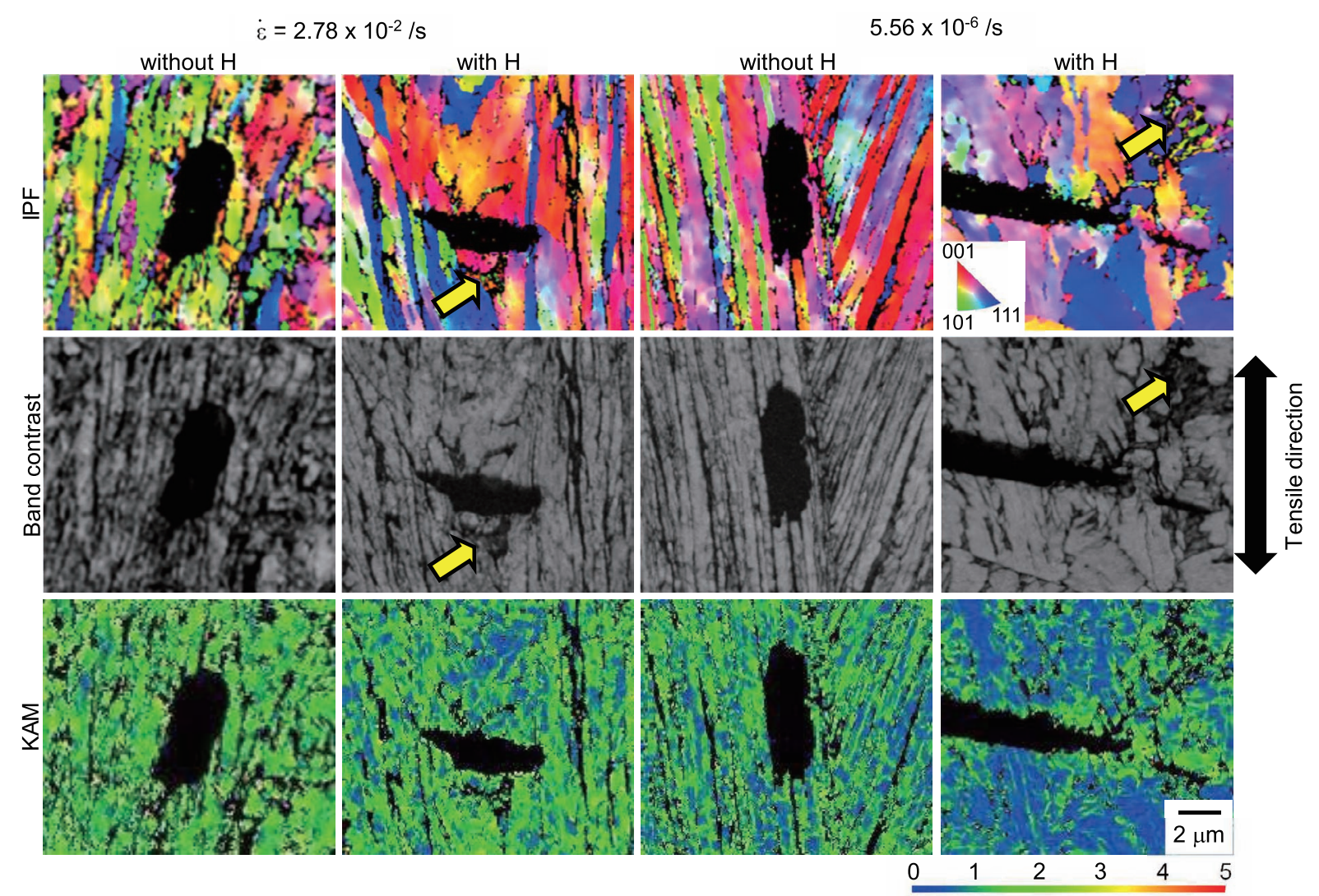

Fig. 9. Inverse pole figure (IPF), band contrast and kernel average misorientation (KAM) maps of cross sectional area near fracture surface of TBF steel tensile tested at strain rates of $5.56 \times 10^{-6}$ and $2.78 \times 10^{-2} / \mathrm{s}$ without and with hydrogen. Arrows represent transformed martensite.

These corrections do not affect main results, discussion and conclusions in the article at all. The authors deeply apologize for causing the readers inconvenience by these mistakes. 